\title{
DENTISTRY AS A PROFESSION IN INDIA: AN OVERVIEW FOR PROSPECTIVE STUDENTS
}

\author{
Tarun Walia'1, Vijay Prakash Mathur², Jatinder Kaur Dhiillon², Gauri Kalra², Vartika Kathuria², \\ 1)Department of Growth \& Development, College of Dentistry, Ajman University of Science and Technology, Ajman, United Arab Emirates. \\ 2) Centre for Dental Education and Research, All India Institute of Medical Sciences, New Delhi, India
}

\section{ARTICLE INFORMATION:}

\section{Article History:}

Received: 29 August, 2013

Accepted in revised form: 11 January

2013

Published: 8 July, 2014

Corresponding author:

Tarun Walia

E-mail: ttww@yahoo.com

\section{Keyword:}

Dentistry, students, courses, postgraduate, training, India

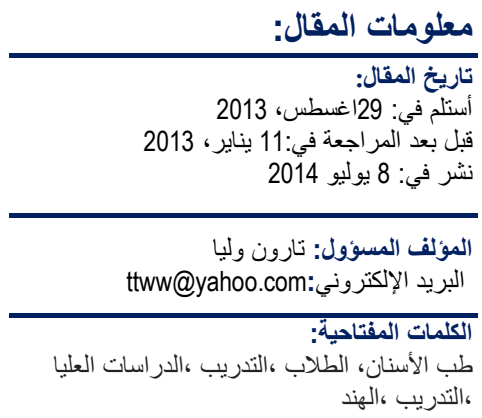

\begin{abstract}
:
India provides high and quality dental education to prospective students pursing dentistry as a profession. Highly trained and experienced teachers coupled with lower fees and great patient exposure makes India an attractive and promising hub for budding dentists. There are numerous options available for Indian and internationally trained dentists to pursue higher qualification in his chosen field of specialization. It is highly recommended that the international candidates aspiring for various courses in dentistry in India should verify the course content and must ensure its recognition from the governing body i.e. Dental Council of India.
\end{abstract}

الملخص العربي

طب الأسنان كمهنة في الهند: مراجعة عامة للطاب الطاب

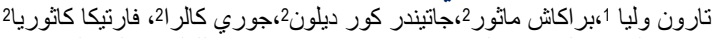


2)مركز تعليم و أبحاث طب الاسنان، معهد عموم الهند للعلوم الطبية، نيو دلهي ، الهند

تقدم الهند تعليم ذو جودة عالية في مجال طب الأسنان للطلاب الر اغبين في هده المهنة

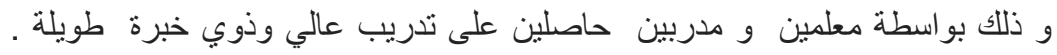

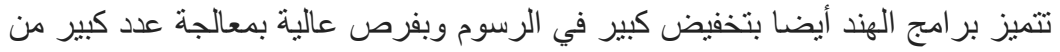

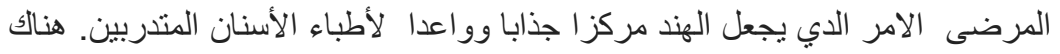

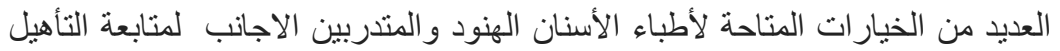





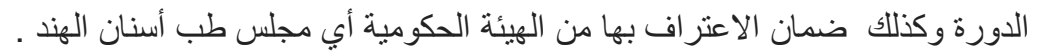




\section{INTRODUCTION:}

I ndia is a highly diverse country with many languages, cultures and religions. India is the second most populous country in the world $^{1}$ and accounts for $21 \%$ of the world's global burden of disease ${ }^{2}$.This is due to factors such as lack of environmental sanitation \& safe drinking water, under-nutrition, poor living conditions, and limited access to preventive and curative health services. Lack of education, gender inequality and explosive growth of population also contribute to increasing burden of disease. Despite great achievements in oral disease prevention globally, problems still remain in many communities all over the world particularly among under-privileged groups in developed and developing countries like India. Economic deprivation in a large segment of Indian population results in poor access to health care. $^{3}$ Poor educational status leads to nonutilization of scanty health services and increase in avoidable risk factors. Health care structure in the country is over-burdened by increasing population. In India, there has been a trend in the increasing number of dental colleges and correspondingly the number of dental surgeons has also increased. However, increase in number of dental professionals could not have significant impact on the incidence and severity of oro-dental problems ${ }^{4}$. India has already created a niche for itself in dentistry and the standard of teaching has been ever improving. Aspirants are now willing to study in India as the cost factor is more pleasing when compared to the western dental schools. Indian dental schools employ highly trained, experienced teachers and experts for teaching thereby increasing the quality of the dental programs offered. Quality education coupled with low costs and promising placements is putting India on the global map as the emerging hub for dental studies.

\section{HEALTH CARE SYSTEM IN INDIA:}

Health care delivery system in India exists to provide better sources and resources for better health. This system includes health centers, clinic, hospitals and nursing homes. The health care system is enhanced through linkages that bring subsystems to provide health care with proper resources, technologies and skills. Eighty percent of Indian population resides in rural areas and due an inadequate distribution of health care service providers in these areas, only
$20 \%$ of people could avail the health care service. Indian health care infrastructure in rural areas has been developed as a three tier system. ${ }^{5}$ As on March, 2011, there are 148124 Sub Centres, 23887 Primary Health Centres (PHCs) and 4809 Community Health Centres (CHCs) functioning in the country. ${ }^{5}$

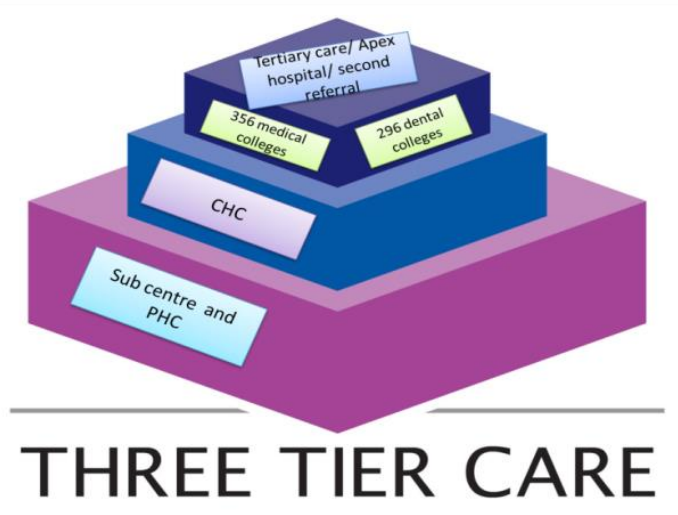

Fig: 1. the three tier model for the dental care system in India.

ORAL HEALTH CARE SYSTEM IN INDIA6:

Oral health has been neglected since ages in India due to meager funds allocation by the government. This has resulted in increased prevalence of dental diseases. Oral health care is delivered at following levels:

1)Government organizations:

a. Government Dental Colleges.

b. Government Medical Colleges with Dental Wing.

c. District Hospitals with Dental Unit .

d. Community Health Centers .

e. Primary Health Centers.

2) Non-governmental Institutions:

a. Private Dental Colleges .

b. Private medical college with dental wing.

c. Corporate hospital with dental units.

3)Private practitioners:

a. Private dental practitioners

b. Private dental hospitals

c. Private medical hospitals with

d. Primary Health Centers dental units

4)Indigenous systems organizations:

a. Ayurveda

b. Sidda

c. Unani

d. Homeopathy 
DENTAL COURSES AVAILABLE IN INDIA:

\section{Undergraduate Degree- Bachelor of Dental Surgery}

Requisite qualification for admission to BDS course is as follows ${ }^{7}$ :

\begin{tabular}{|l|l|l|}
\hline $\begin{array}{l}\text { Age } \\
\text { requirement }\end{array}$ & $\begin{array}{l}\text { He/She has completed age of 17 years at the time of } \\
\text { admission or will complete the age on or before 31st } \\
\text { December of the year of his/her admission to the 1st } \\
\text { year BDS Course and is an Indian national. }\end{array}$ & $\begin{array}{l}\text { The upper age limit is 25 years as on } \\
31^{\text {st }} \text { December of the year of the } \\
\text { entrance examination. }\end{array}$ \\
\hline $\begin{array}{l}\text { Qualifications } \\
\text { For Indian } \\
\text { nationals and } \\
\text { OCI }\end{array}$ & $\begin{array}{l}\text { The Higher/Senior Secondary Examination or the Indian } \\
\text { School Certificate Examination which is equivalent to } \\
\text { 10+2 Higher/Senior Secondary Examination after a } \\
\text { period of 12 years study, the last two years of such study } \\
\text { comprising of Physics, Chemistry, Biology/Bio- } \\
\text { technology (which shall include practical tests in these } \\
\text { subjects) and Mathematics or any other elective subject } \\
\text { with English at a level not less than the core course for } \\
\text { English as prescribed by the National Council of } \\
\text { Educational Research and Training after introduction of } \\
\text { the 10+2+3 educational structure as recommended by } \\
\text { the National Committee on Education. }\end{array}$ & $\begin{array}{l}\text { year } \\
\text { English, Physics, Chemistry (Organic } \\
\text { and Zoology) after passing the } \\
\text { Higher Secondary or Pre-University } \\
\text { Examination. }\end{array}$ \\
\hline
\end{tabular}

Duration of BDS course is four calendar years with one year paid compulsory rotating internship in the dental colleges. Other undergraduate degree courses such as in Dental Hygiene, Dental technology and Dental

\section{POST GRADUATE DEGREE COURSES (MASTER OF DENTAL SURGERY):}

Master of Dental Surgery or MDS is a three year post graduate degree offered by almost all dental colleges in India in all the dental specialities. Minimum requirement is a recognized BDS degree awarded by an Indian University in respect of recognized Dental College under Section 10(2) of the Dentists Act, 1948 or an equivalent qualification recognized by Dental Council of India and should have obtained
Assistance are also available in some of the dental institutions in India. The details of all such courses are available on the website of the Dental Council of India.

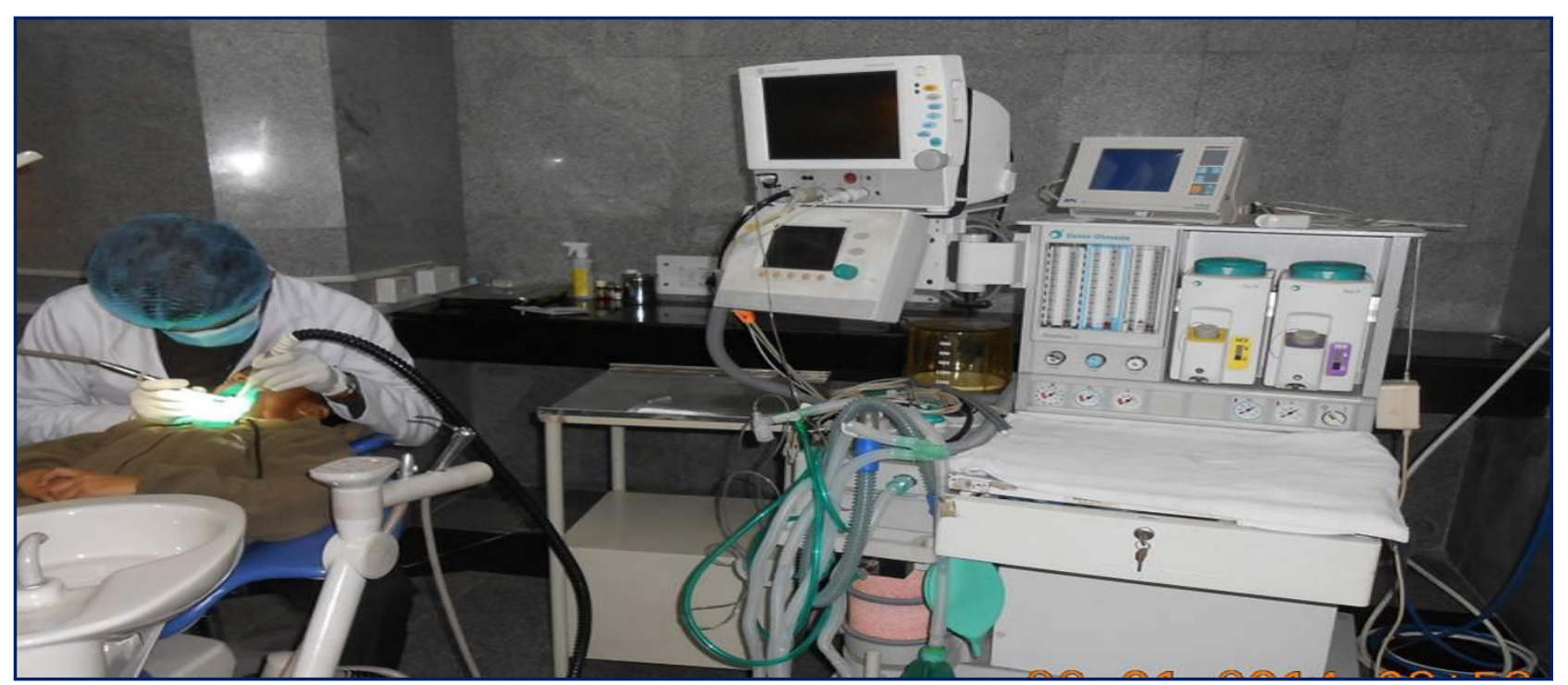

Fig:2.Conscious Sedation room in Oral Health Sciences Centre, Post Graduate Institution of Medical Education \& Research (PGIMER, Chandigarh), a premier post graduate dental institution of India.

Citation:Libyan Dent J 2014, 4:1611648 - http://dx.doi.org/10.5542/LDJ.v4i0.1611648 


\section{FOREIGN NATIONALS - MANAGEMENT QUOTA, NOMINATIONS BY GOVT:}

In case an Indian citizen possesses a primary dental qualification/PG diploma/Post Graduate Dental qualification awarded by any dental institution outside India, he/ she is required to undergo a screening test as per the Dental Council of India Screening Test Regulations (2009) along with a compulsory clinical competence training for a period of 12 weeks under the guidance of a specialist in the concerned speciality at a dental Institution specified by the Dental Council of India for the purpose. Students with postgraduate dental qualifications awarded in countries such as Australia, Canada, New Zealand, United Kingdom \& United States of America that are recognized for enrolment as dental practitioners in the concerned specialties in the respective countries need not appear for the screening test.

The minimum qualifying marks for the written examination in screening test are $50 \%$. Candidates who clear the written exam are called for viva voce. A maximum of three attempts are allowed to clear the exam. In order to be eligible to appear for the screening test, the candidate also needs to obtain an eligibility certificate. The details of the certificate as well as the screening test are available in the Dental Council of India notification number DE-1472009 dated 13th August, 2009.

\section{PG DIPLOMA COURSES IN DENTISTRY:}

Plenty of Post Graduate Diploma courses are available in India. Minimum eligibility criteria for pursuing any PG Diploma course is a BDS degree from a college and University recognized by Dental Council of India or an equivalent qualification recognized by the Dental Council of India. Candidates not possessing a recognized Dental qualification for the above purpose should secure the prior approval of his qualifications by the Dental Council of India before he / she can be admitted to the Diploma courses in any of the Universities in India. Students for such courses shall be selected strictly on the basis of their academic merit. Academic merit is determined by any institution / university through a competitive test either at state government level or at Central level followed by the cumulative performance of the candidate in respective academic years during BDS degree. IGNOU in collaboration with DCI has developed two post graduate certificate programs for BDS graduates. The duration is from 1 to 3 years. They are:

1) PG Certification in Oral Implantology 9

2) $\mathrm{PG}$ Certification in Endodontics ${ }^{9}$

Many other foremost institutions in India in collaboration with Dental council of India have come up with PG Diploma courses in all specialties with the duration of 2 years. The courses are listed below ${ }^{10,11,12}$ :

1) PG Diploma in Conservative Dentistry, Endodontics \& Esthetic Dentistry

2) PG Diploma in Periodontology \& Oral Implantology

3) PG Diploma in Oral \& Maxillofacial Surgery \& Oral Implantology

4) PG Diploma in Orthodontics \& Dentofacial Orthopedics

5) PG Diploma in Oral Medicine \& Radiology

6) PG Diploma in Prosthodontics, Crown \& Bridge \& Oral Implantology

7) PG Diploma in Public Health Dentistry \& Preventive Dentistry

8) PG Diploma in Peadodontics \& Preventive Dentistry

Another PG diploma course is available in Dental materials with minimum eligibility of BDS degree. It is of two years ${ }^{13}$.

\section{SCOPE :}

After pursuing any of the Diploma courses, a candidate is open to a variety of options in his/ her dental career such as teaching in dental colleges, clinical research, and job in biomedical industries and can also approach speciality dental private practice.

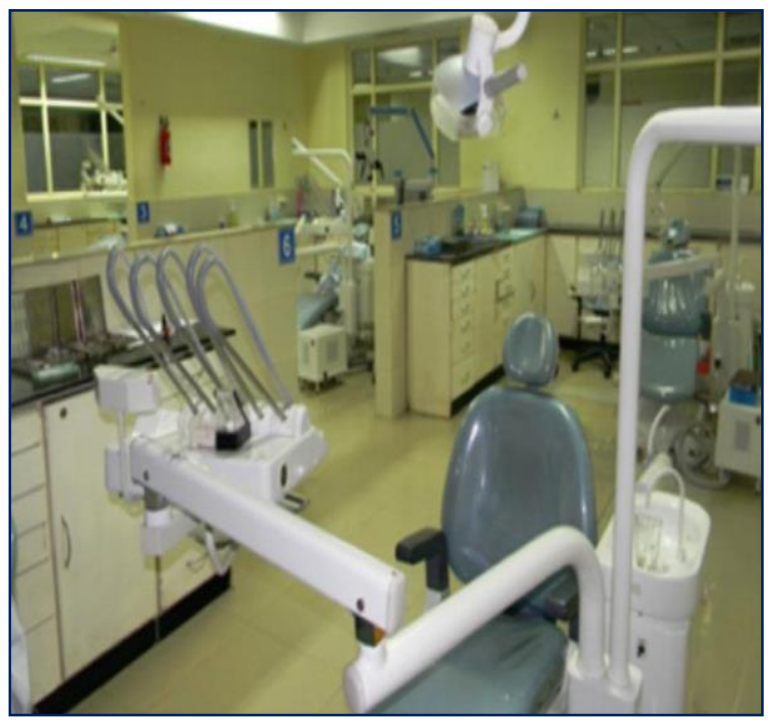

Fig: 3. A typical set up of an Indian educational institute imparting dental training. 


\section{ADVANCED COURSES:}

Two courses at advance level are also available in Indian universities for aspiring candidates who majorly opt for clinical dental practice. Minimum qualification required for an Indian national is BDS degree.

I.Oral Implantology (Duration 1 year)

The training involves didactic component, hands on experience on dummy jaw, clinical live surgeries (demonstrations) on patients and cases by students and training for prosthetic work. Candidate is also allowed to place few implants on live patients too.

II. Aesthetic Dentistry (Duration 1 year)

This extensive certificate course is designed to provide a wide-ranging experience in all aspects of aestheticl cosmetic and contemporary restorative dentistry. It also provides opportunities to master advanced aesthetic techniques using a variety of contemporary materials. ${ }^{14}$

\section{FELLOWSHIP PROGRAMMES IN DENTAL SPECIALTY:}

Recently, a number of fellowship programmes ${ }^{15}$ have been introduced in collaboration with DCI. The course is full time with the duration of 1 year. The basic eligibility is MDS in respective specialty. The courses offered are:

1) Fellowship in Cleft Lip and Palate (Eligibility: MDS in Oral \& Maxillofacial Surgery, MS - General Surgery, MS-ENT)

2) Fellowship in Aesthetic Facial Surgery (Eligibility: MDS in Oral \& Maxillofacial Surgery, MS - General Surgery, MS - ENT)

3) Fellowship in Maxillofacial Prosthodontics (Eligibility: MDS in Prosthodontics)

4) Fellowship in Implant Dentistry/ Aesthetic Dentistry (Eligibility: BDS)

\section{CERTIFICATE COURSES:}

Other short term courses available are certificate courses in Dental mechanics, Dental Assistant and Dent Hygienist, with two years of duration. Minimum qualification required is as follows ${ }^{16}$ :

i. A candidate should be at least 15 years of age at the time of admission or within 3 months of it and should be medically fit;

ii. A candidate must have passed at least Matriculation examination of a recognized University taking Science subjects or an equivalent recognized qualification.

Duration of course: 2 years Excellent scope for employment with the Private Practitioners, Dental Laboratories, Dental Institutions, Dental Hospitals, Armed Forces etc .There exists an uncertainty in the admission criterion for candidates of foreign origin to these courses. Thus, DCI may be contacted for further queries.

\section{DOCTORAL DEGREE (PhD):}

There are several universities offering $\mathrm{PhD}$ in various dental specialties and M.Sc. in Dental Materials in the country. Each university has different entrance examination for the doctoral courses; however foreign nationals can also apply freely to such courses. Duration for the doctorate courses is between three to five years for candidates having post-graduation. Admission is through the state/ Central Government entrance examination or by the independent university and is based on merit. M.Sc. (Dental Materials) is a two year post graduation degree programme with basic eligibility of BDS (recognized by DCI) and B.Sc. graduates. Admission to the course is through a screening test. All candidates (Indian/NRI/ Foreign) are eligible for the same $^{17,18}$.

\section{CLINICAL RESEARCH:}

IndianClinical Data Management and Pharmacovigilance industry is witnessing a boom with growth rate of over $30 \%$ per annum and the Clinical Trials area is also undergoing phenomenal growth in India. Industry demands more than 50,000 trained professionals in the coming years in various domains related to Clinical Research. There are multiple career opportunities in Pharmaceutical companies, CROs (Contract Research Organization), Hospitals, Clinics, Regulatory Affairs. Aspiring candidates may join as Clinical Research Associate, Clinical Research Coordinator, Investigators and Co-investigators.

\section{HOSPITAL ADMINISTRATION:}

Masters in hospital administration (MHA) is a two year course being conducted by various private universities in India. It encompasses various aspects of administration such as operations \& management, health policy\& economics, healthcare finance, health information technology and leadership in healthcare organizations.

CAREER OPPORTUNITIES IN DENTISTRY IN INDIA: 
Tarun Walia et al

In the present scenario, dentistry has gained great interest of students seeking career in health care and has successfully motivated the candidates to pursue in the same field. During 1990 's, these courses were not as popular as they are showing today that dental health has gained importance. India provides a suitable alcove to various international aspiring dental professionals in various ways. Being a largely populated country with diverse ethnicities, cultures \& habits and also with unmet oral health care needs, varied spectrum of patients with different diseases can be seen and treated. When healthcare system is concerned, a disparity can be seen in the availability of health care facilities in our country among various socioeconomic classes. The middle and upper classes, which generally live in the urban areas of India, have access to quality medical care. However, the majority of India lives below the poverty line in rural areas and has extremely limited access to medical care. The stark inequality of available healthcare system provides a bay for enhanced patient care in unprivileged areas. The low studying costs with quality education and a great patient exposure accounts for numerous career possibilities in dentistry in our country for the national as well as international candidates. Comprehensive undergraduate as well as post graduate degree and diploma courses are available for aspiring dental professionals.

\section{RECOMMENDATIONS:}

It is highly recommended that the international candidates aspiring for various courses in dentistry in India should verify the course content and must ensure its recognition from the governing body i.e. Dental Council of India. Overseas students should corroborate the recognition status of the post graduate degree/ PG Diploma degree acquired from India in their country or where they wish to practice. In case of any further information required, the website of Dental Council of India can be accessed. ${ }^{8}$ (www.dciindia.org)

\section{REFERENCES:}

1) http://www.who.int/topics/global_burden_of _disease/en/. Last accessed on May 4, 2013.
2) http://www.who.int/countryfocus/cooperation _strategy/ccsbrief_ind_en.pdf. Last accessed on May 4, 2013.

3) http://dget.gov.in/cirtes/csc/courses/Admissio n_to_dental_courses.htm. Last accessed on May 9,2013)

4) http://www.dciindia.org/dciregulation_2006_ pages/pdf_files/Revised\%20MDS\%20Course $\% 2$ 0Regulations\%202007.pdf); Accessed on 14th May, 2013

5) nrhmmis.nic.in/.../Rural\%20Health\%20Care $\% 20$ System\%20in\%20 India. Last accessed on May 5, 2013.

6) Screening.iarc.fr/.../Oral_Health_Oro-

Dental_Problem_WHO_Project_. Last accessed on May 5, 2013.

7) http://www.sppgidms.org/pg_diploma.html. Last accessed on 2nd May, 2013.

8) www.rguhs.ac.in. Last Accessed on 1st May, 2013

9) http://www.dmimsu.edu.in/?SPDC=academic _courses. Last Accessed on 1st May, 2013

10) http://www.manipal.edu/Institutions/Dentistr y/MCODSManipal/Results/PGDiploma/Pages/P ostGraduateDiplomaCourseinDentalMaterials.as px. Last Accessed on 1st May,2013.

11) http://www.manipal.edu/Institutions/Dentistr y/MCODSManipal/Results/AdvancedCourses/P ages/Welcome.aspx. Last Accessed on 1st May, 2013.

12) www.rvdentalcollege.org. Last Accessed on 1st May, 2013.

13) http://www.manipal.edu/Institutions/Dentistr y/MCODSManipal/Results/CertificateCourse/Pa ges/Welcome.aspx. Last Accessed on 1st May, 2013.

14) http://www.manipal.edu/Institutions/Dentistr y/MCODSManipal. Last Accessed on 1st May, 2013.

15) www.rvdentalcollege.org. Last Accessed on 1st May, 2013

16) Certificate course in Dental Mechanics, Dental Assistant and Dent Hygienist. Last Accessed on 1st May, 2013. Available at: http://www.manipal.edu/Institutions/Dentistry/ MCODSManipal/Results/CertificateCourse/Pag es/Welcome.aspx.

17) Post Graduate Diploma in Dental Materials. Last Accessed on 1st May, 2013. Available at: http://www.manipal.edu/Institutions/Dentistry/ MCODSManipal. 